Working Paper 9312

\title{
BUSINESS CYCLES AND AGGREGATE LABOR-MARKET FLUCTUATIONS
}

by Finn E. Kydland

Finn E. Kydland is a professor of economics in the Graduate School of Industrial Administration at Carnegie-Mellon University, Pittsburgh, and a research associate at the Federal Reserve Bank of Cleveland. This research was supported by the National Science Foundation. The author thanks Christian Zimmermann for research assistance.

Working papers of the Federal Reserve Bank of Cleveland are preliminary materials circulated to stimulate discussion and critical comment. The views stated herein are those of the author and not necessarily those of the Federal Reserve Bank of Cleveland or of the Board of Governors of the Federal Reserve System.

December 1993 


\section{ABSTRACT}

This paper describes some of the recent findings about the cyclical behavior of the aggregate labor market and its relation to the overall business cycle. The basic theoretical framework is the neoclassical growth model with its central component: the aggregate production function. After listing the main empirical regularities related to the labor input, the paper presents some of the developments in theory and measurement that have been motivated by these facts. Examples are the roles of household production, of the differences in cyclical behavior of workers with different skills, and of the fact that labor-input changes take the forms of both employment and hours-per-worker movements. 


\section{Introduction}

Central to business-cycle theory as well as to growth theory is the aggregate production function, which relates the nation's output of goods and services to the inputs of capital and labor. The behavior of the labor input is of prime importance to business-cycle theory. For growth, most of the output change is accounted for by changes in technology and in capital. In contrast, perhaps on the order of two-thirds of the business cycle is accounted for by movements in the labor input and one-third by changes in technology. Thus, most business-cycle theorists agree that an understanding of aggregate labor-market fluctuations is a prerequisite for understanding how business cycles propagate over time.

Table 1 lists statistics describing the cyclical behavior of key U.S. aggregates that are related to the labor input. The table includes measures of cyclical volatility, as well as correlations with cyclical real GNP, contemporaneously and at leads and lags of up to five quarters. The logarithms of the original series were detrended using the Hodrick-Prescott filter before the statistics were computed. (See Kydland and Prescott [1990] for details.) Some of the cyclical series are plotted against cyclical real GNP in Figures 1-6.

Notable regularities related to the labor market are:

(i) Aggregate hours, whether measured by the household or the establishment (payroll) survey, is almost as volatile as is real GNP.

(ii) The household survey indicates that approximately two-thirds of the total-hours fluctuation is in the form of variation in employment and one-third in hours per worker. 
(iii) Aggregate hours is highly procyclical, as indicated by the contemporaneous correlation coefficients with real GNP of nearly 0.9 .

(iv) Hours displays a slight phase shift in the direction of lagging the cycle, especially in the employment component. Hours per worker displays almost no phase shift, or perhaps a slight lead.

(v) Average labor productivity is somewhat procyclical and leads the cycle. The degree of procyclicality is greater when output is divided by hours measured according to the household survey. The hours from the establishment survey indicate the longest lead: two to three quarters.

(vi) The statistics for average real hourly compensation in the business sector (which produces about 85 percent of GNP) are quite similar to those for productivity. If, on the other hand, we divide total employees' compensation from the national income accounts by total hours from either survey, series result whose correlations with real GNP are much lower.

(vii) Some writers have focused instead on the correlation of compensation (or productivity) with hours rather than with GNP (for example, Christiano and Eichenbaum [1992]). As a reflection mainly of the longer phase shift, the compensation series are less correlated contemporaneously with hours than with real GNP.

(viii) Real labor income is procyclical, but labor income as a fraction of GNP is countercyclical.

(ix) Over time, real hourly compensation has risen dramatically while hours worked per household has remained about constant or even declined slightly. Cross-sectionally, however, there is a clear positive 
correlation between hours worked and the real wage. Moreover, the volatility of annual hours of work is substantially greater for lowwage than for high-wage earners. A source of such information is the University of Michigan's Panel Study of Income Dynamics (PSID). Ríos-Rull [1993a] divides a large sample of working-age individuals of both sexes and all ages into five groups according to their average real wage over the sample period (1969-82). The brackets, in 1969 dollars per hour, are 2.0 or less, $2.0-2.8,2.8-3.8,3.8-5.3$, and over 5.3, resulting in fairly similar-sized groups. Within these groups, the average per-person standard deviations of annual hours of work were, respectively, 579, 529, 479, 415, and 341 . (See his Table 2.)

(x) Benhabib, Rogerson, and Wright (1991) and Murphy, Shleifer, and Vishny (1989) argue that hours allocated to the production of consumption goods are procyclical. While direct observations based on a clear classification of the goods produced are not readily available, empirical evidence reported by Murphy, Shleifer, and Vishny points in that direction.

At various stages in the recent development of business-cycle theory, some of these cyclical patterns have been regarded as deviations from existing theory. An application of real-business-cycle theory has been to address the question: How much of post-World War II business cycles would have remained if technology shocks were the only source of fluctuations? Major deviations along dimensions central to this question obviously could reduce one's confidence in the quantitative answer obtained. Through the interaction of theory and measurement, the deviations or anomalies relative to theory have led to stronger theory as well as to better measurements. 
This paper has two main objectives. The first is to give examples of the perceived deviations or anomalies relative to theory, especially those connected with labor-market fluctuations, and of how researchers have attempted to resolve them. In the process, it will become clear that some of the proposed modifications still leave open important theoretical and measurement issues. The paper's second objective is to present in detail an example of a model environment that is reasonably rich in its description of the labor market. It will incorporate movements of labor inputs in the forms of hours per worker as well as employment -- both the intensive and the extensive margins.

In the next section, I present as a benchmark the standard neoclassical stochastic growth model extended to include an explicit role for time allocation. It can be regarded as the starting point for addressing business-cycle questions. Then I review some of the developments in theory and measurement that have been motivated by perceived deviations from established theory. One such development is to consider the use of nonmarket time in the household, possibly jointly with other inputs, to produce nonmarket goods. This is the subject of Section 2. Section 3 considers the fact that the work force consists of workers with a wide range of skills and whose behavior over the cycle differs substantially. This issue is discussed both from a modeling standpoint and from the perspective of measuring the labor input in aggregate production. The model formulations described in Sections 2 and 3 represent, with today's methods, relatively tractable extensions of basic neoclassical theory.

Section 4 deals with the implications for the business cycle of the fact that labor-input changes take the forms of both hours-per-worker and employ- 
ment changes. The significance of introducing the employment margin became clear from the important paper by Hansen (1985) based on the theoretical insight of Rogerson (1984, 1988). The methodological foundation permitting the introduction of both margins has been developed only recently. A fundamentally new issue in this context is what shape the production function should take. In the business sector, the change of output associated with a given change of total hours in a given period surely is different when the change is in the number of hours a plant is being used rather than in the number of workers operating the plant.

This paper presents several ways in which the roles of market and nonmarket time for business cycles have been modeled. Section 5 provides a comparison of four of these in terms of the main business cycle characteristics. Section 6 contains an example of how one can extend one of these model economies (the one presented in Section 4) to incorporate a new feature, in this case learning by doing.

Finally, in the last section I attempt an assessment of where we stand, particularly regarding the labor market's contribution to the propagation of shocks.

\section{Basic Business Cycle Framework}

Neoclassical growth theory has become the dominant theoretical framework in quantitative business-cycle theory, as well as in most other areas of aggregate economics. It represents an environment that includes household and business sectors, and, for some questions, a government sector as well. The simplest growth model ignores time-allocation decisions. (See Stokey and Lucas [1989, Ch. 2]). A version which still is simple, but which contains 
enough ingredients potentially to address business-cycle questions, is as follows: The economy is inhabited by a large number of identical households whose preferences are represented by a utility function

$$
E \sum_{t=0}^{\infty} \beta^{t} u\left(c_{t}, \ell_{t}\right)
$$

where $c_{t}$ is consumption, $\ell_{t}$ is time spent in nonmarket activity (or leisure for short), and $\beta$ is the subjective discount factor. The production technology uses as inputs capital, $k_{t}$, and labor, $h_{t}$. There is perfect substitution in production between investment, $x_{t}$, and consumption. The constraints on the uses of output and time are

$$
\begin{aligned}
& c_{t}+x_{t} \leq z_{t} f\left(h_{t}, k_{t}\right), \quad \text { and } \\
& h_{t}+\ell_{t} \leq 1
\end{aligned}
$$

where, for simplicity, total discretionary time (net of sleep and personal care) is normalized to one. Laws of motion for the capital stock and technology are

$$
\mathbf{k}_{\mathrm{t}+1}=(1-\delta) \mathbf{k}_{\mathbf{t}}+\mathbf{x}_{\mathrm{t}}
$$

$$
z_{t+1}=\rho z_{t}+\varepsilon_{t+1}
$$

where $\varepsilon_{t+1}$ is a random disturbance with positive mean.

This framework departs from the simplest neoclassical growth framework in two ways. Leisure is included in the utility function, a feature from which models designed to address growth questions usually abstract. The emphasis on the time-allocation decision distinguishes business-cycle theory from growth theory. Another extension is the inclusion of stochastic technology shocks, which have been considered in the theoretical growth literature by Brock and Mirman (1972) and by Danthine and Donaldson (1981). With 
these features included, one could use the model to address, for example, questions about the role of technology shocks. Following Solow (1957), the $z^{\prime} \mathbf{s}$ can be measured as the residual in output variation after the capital and labor inputs have been accounted for. With the Cobb-Douglas production function,

$$
f\left(h_{t}, k_{t}\right)=h_{t}^{\theta} k_{t}^{1-\theta},
$$

one can write

$$
\log z_{t}=\log G N P_{t}-\theta \log h_{t}-(1-\theta) \log k_{t} .
$$

The value of $\theta$ corresponds to the average labor share in GNP. By studying the resulting series of $z^{\prime} s$, one can characterize statistically their persistence, as reflected in the parameter $\rho$ in (1.1), as well as the volatility of the innovations $\varepsilon$.

With explicit forms for the $u$ and $f$ functions and numerical values for the parameters of these functions and of the laws of motion, one can compute the solution in the form of decision rules for the variables $c_{t}, n_{t}$, and $x_{t}$. These decision rules, along with the laws of motion for the state variables, $k_{t}$ and $z_{t}$, and the stochastic specification of the random shocks, can be used to perform computational experiments with the aim of yielding quantitative answers to business-cycle questions.

A standard utility function is

$$
u\left(c_{t}, \ell_{t}\right)=\left(c_{t}^{\alpha} \ell_{t}^{1-\alpha}\right)^{1-\sigma} /(1-\sigma)
$$

Here, the elasticity of substitution between consumption and leisure is one. In the general class of constant-elasticity-of-substitution (CES) functions, this is the only value consistent with the observation that, in spite of a 
large increase in the average real wage over the past few decades, there has been virtually no change in long-run hours per household in market activity. In a model of this type, this fraction of long-run time spent in market work typically turns out to be close to the value of the parameter $\alpha$. Thus, with measurement of this fraction from data on individuals or households, its average value implies a value for $\alpha$. Such time-allocation measurements were reported by Ghez and Becker (1975) who, when defining the total discretionary time available for market and nonmarket activity, were careful to measure and exclude time devoted to sleep and personal care.

Determining values of $\theta$ and $\alpha$ as well as of the elasticities of substitution in the utility and production functions are examples of calibrating the model economy. The curvature parameter $\sigma$ is harder to quantify with confidence. Studies of attitudes towards risk may suggest a reasonable range for this parameter.

Business-cycle theory organizes quarterly national income and product accounts (NIPA) data. With this period length, however, it makes a difference that building new factories takes much longer than one quarter. AccordIngly, Kydland and Prescott (1982) assume that the construction of productive capital in the business sector takes $J$ quarters, where $J$ on the average may be three or four, but with resources used throughout the construction period. The law of motion for the productive capital stock then is

$$
\mathbf{k}_{\mathrm{t}+1}=(1-\delta) \mathbf{k}_{\mathrm{t}}+\mathbf{s}_{1 \mathrm{t}},
$$

where the notation is to let $s_{j t}, j=1, \ldots, J$, be capital (in units of $f$ inished capital) that is $\mathrm{J}$ periods from completion. Thus,

$$
s_{j, t+1}=s_{j+1, t}, \quad j=1,2, \ldots, J-1 .
$$


The amount of resources used at each stage when building one unit of new productive capital is $\varphi_{j}$. Total investment, the sum of fixed investment and inventory investment, then is

$$
x_{t}=\sum_{j=1}^{J} \varphi_{j} s_{j t}+y_{t+1}-y_{t},
$$

where $y_{t}$ is the inventory stock at the beginning of period $t$. Including inventories is another way of extending the standard growth model. In a period with high productivity, for instance, people may wish to smooth consumption and carry into the subsequent quarter some finished goods in the form of inventories. Moreover, as motivated in Kydland and Prescott (1982), the inventory stock may be treated as an input in aggregate production. A specification of the resource constraint then is

$$
c_{t}+x_{t} \leq\left[(1-\gamma)\left(z_{t} h_{t}^{\theta} k_{t}^{1-\theta}\right)^{-\nu}+\gamma y_{t}^{-\nu}\right]^{-1 / \nu} .
$$

With these features added, the model environment accounts quite well for the key properties of postwar U.S. business cycles. They include relative volatility of investment and consumption, the procyclicality of most aggregates, and the contemporaneously uncorrelated capital stock. The model yields the preliminary estimate that technology shocks account for more than half of postwar U.S. business cycles. This estimate follows from computational experiments which use as an input the volatility of Solow residuals obtained for the U.S. economy; it is based on the fraction of U.S. output volatility implied from the model economy. This finding is supported by the model behavior of other aggregates, such as relative consumption and investment fluctuations. The key deviation relative to theory is that, in this simple model with everyone working the same number of hours, the percentage standard deviation of the hours is substantially smaller than that of the 
model's real GNP.

\section{Household Production}

The realization that the empirical procyclical volatility of hours possibly may be a problem for a general equilibrium theory of the cycle dates back at least to Lucas and Rapping (1969). Confronting this issue, they were led to a question: Are there reasons to substitute intertemporally, not captured by the standard specification of the household problem, that give rise to greater procyclical hours volatility? Lucas and Rapping suggest the theoretical possibility that future utility may depend, in part, directly on this period's choice of hours of work.

Kydland and Prescott (1982) make this idea operational and represent preferences in such a way that current utility is a function of a weighted average of current and past choices of nonmarket time:

$$
u\left(c_{t}, \mu(L) \ell_{t}\right)=\frac{1}{1-\sigma}\left[c_{t}^{\alpha}\left(\sum_{1=0}^{\infty} \mu_{i} \ell_{t-i}\right)^{1-\alpha}\right]^{1-\sigma} .
$$

With weights summing to one, as can be assumed without loss of generality, their choice of parameter values was to let as much as one-half of the weight fall on current leisure $\left(\mu_{0}=0.5\right)$, with the remainder spread over the past with geometrically declining weights. Thus, continuing with this numerical example, if the weights decline by 10 percent per quarter, then $\mu_{1}=0.05$, $\mu_{2}=0.045$, and so on. With that specification, the dependence of utility on current and past leisure choices is characterized by two parameters, $\mu_{0}$ and $\eta$, where $\eta$ is the rate of decline of the weights, that is, $\mu_{i+1}=(1-\eta) \mu_{i}$ for all $1 \geq 1$.

Kydland (1984a) interprets this utility function as a stand-in for 
household production in which part of nonmarket time is used to accumulate household capital which yields utility in the future. Examples of such capital may be quality of children, health, and perhaps the quality of the residence and other durable household property. The relatively large weight $\alpha_{0}$ on current nonmarket time then reflects the notion that a substantial portion of nonmarket time yields immediate pleasure. The remainder represents an investment in a form of household capital which depreciates at a rate of $\eta$. This analog of the specification above to the household production idea is exact when the two uses of nonmarket time are in fixed proportions and leisure and the durable home goods are perfect substitutes in preferences. These are conservative assumptions. Relaxing them presumably would make market hours more responsive to changes in market opportunities.

With this feature included, not only does the volatility of hours increase relative to those of productivity and output, but technology shocks are also more potent in generating overall business-cycle volatility. Referring to those findings, Kydland (1984b) concludes: "Using a standard timeseparable utility function, about two-thirds of the fluctuations in the data were accounted for. If households are assumed to value leisure more if they have consumed less leisure in the past, the growth model explained nearly all."

This preliminary statement was not based on direct measurements of the volatility of the technology shocks. A more precise estimate can be based on measurements included in Prescott's (1986) survey of the status of real business cycles at that time. They are based on Solow's (1957) method for measuring technological change as the residual after the inputs have been accounted for. Subsequently, the resulting estimate of the volatility of the 
Solow residual has been used in computational experiments with a variety of model economies. The statistical properties of these residuals indicate that they are highly persistent, that is, that they have high serial correlation. On the basis of these estimates, instead of "two-thirds," the number in the above quotation would have been 55 percent.

The fact remains that the quantitative importance of household capital formed by past nonmarket time can make a substantial difference to the estimate of the role of technology shocks. An attempt at assessing independently the magnitude of this form of household capital is made in Hotz, Kydland, and Sedlacek (1988). Using annual panel data for 482 men who in the first year of the twelve-year sample period were between the ages of 23 and 52 , they estimate the parameters characterizing the role of household capital for life-cycle behavior, taking into account differences in age, number of children, and other demographic factors. The estimates are consistent with the parameter values for $\mu$ and $\eta$ used by Kydland and Prescott (1982). It is probably fair to say, however, that this feature of household production has not been sufficiently verified by measurements to be regarded as necessary for a rellable estimate of the role of technology shocks for the cycle.

This formulation of time as an input into producing a form of household capital is simple and abstracts from the possibility that market-produced goods may be required as a joint input. The general idea, however, that attention to household production is important for understanding labor-market fluctuations is an appealing one. It has been pursued in greater detail in two recent papers, by Benhab1b, Rogerson, and Wright (1991) and by Greenwood and Hercowitz (1991). Both these papers consider the use in the household of physical capital (residential housing and/or consumer durables) which, along 
with nonmarket time, can be used to produce consumption goods. Greenwood and Hercowitz focus on the joint pattern of capital accumulation in the business and household sectors. Although this issue has indirect implications for the labor input in market production, I shall not undertake a discussion of that topic at this time. Benhabib, Rogerson, and Wright (BRW), on the other hand, address issues that have a more direct bearing on the labor market. For example, they are motivated partly by the impression that fact $(x)$ on page 3 represents a deviation from standard business-cycle theory.

A key feature in the BRW model is the inclusion of a commodity made in the home using time and capital as inputs in a way analogous to the production of the market good. This home-produced consumption good is an imperfect substitute for market goods. Home production is a function of technology shocks in a manner analogous to that of the business sector.

The utility function is similar to relation (1.3), except that the variable $c_{t}$ is replaced by a CES aggregator function representing a composite consumption good which depends on $c_{m t}$ and $c_{n t}$, where the subscripts $m$ and $n$ stand for market and nonmarket, respectively. Leisure in the utility function is net of time allocated to market and nonmarket production: $\ell_{t}=1-h_{m t}-h_{n t}$. Investment goods are produced in the market sector only. Capital can be moved between the two sectors. In practice, this reallocation takes place mostly in the form of new investment. The home and business technologies both are Cobb-Douglas, with share parameters calibrated separately. The laws of motion for the technology shocks in the two sectors are identical, including a serial correlation coefficient of 0.95 .

In addition to the motivation already mentioned, BRW refer to measurements indicating that the fraction of nonmarket time devoted to production in 
the household is large. An interesting question, then, is whether household production may interact with market production in such a way that, combined, technology shocks to market and household production account for a considerably larger fraction of the business cycle than do those of the market sector alone. The answer hinges on three parameters. Indeed, a main contribution of the article is to demonstrate this fact. Since measurements of these parameters are either lacking or rudimentary at best, the article underlines the importance of such measurements for a reliable answer.

Among those three parameters, the key one is the elasticity of substitution in preferences between market- and home-produced consumption, which BRW set equal to five. This figure is based partly on estimates in Eichenbaum and Hansen (1990), according to which there is little statistical evidence against the hypothesis of perfect substitution elasticity between nondurable goods and services and the services of durables. This empirical result can be interpreted as having a bearing on the model at hand. The estimate, however, is hard to reconcile with the observation that, over time, the price of durables relative to nondurables and services has fallen while the expenditure share has remained roughly constant. This fact would suggest an elasticity much closer to one than to infinity. Thus, one may doubt whether the elasticity used by BRW will hold up under empirical scrutiny. Clearly, it plays a significant role for the model properties.

Other new parameters in the home-production specification are the standard deviation of the innovation to home technology and its contemporaneous correlation coefficient with the innovations in business-sector technology. Again, good measurements upon which to base the values are not available. It seems much less likely, however, that the findings hinge upon future measure- 
ments of these parameters. For one thing, the authors make a good case for their reasonableness. Also, the theoretical findings appear not nearly as sensitive to variations within a reasonable range of these parameters.

BRW find that for their economy in comparison with the standard growth model, the volatility of output rises from 1.29 to 1.71 percent, which is very close to that observed for the postwar U.S. economy. The volatility of hours in relation to that of GNP, $s t d\left(h_{m}\right) / s t d(G N P)$, rises from 0.50 to 0.75 .

The correlation in the model between real GNP and hours spent producing consumption goods in the market sector is 0.10 . This magnitude may strike the reader as quite disappointing. One contribution of the article, however, is to show that this correlation can be turned from a large negative value to this slightly positive value simply through the introduction of household production. The simplicity of the model environment in other respects accounts for the negative correlation in the benchmark model. There are several reasons, of which perhaps the most important is the omission of inventories. Changes in business inventories have been procyclical and highly volatile, and a large part of those changes in every quarter has been in consumption goods. For instance, if inventory changes were divided between consumption and investment goods in the same proportion as their average fractions of GNP (about three-fourths and one-fourth, respectively), then a standard business-cycle model without explicit household production, such as that described at the end of Section 1, would imply a positive correlation between real GNP and the hours spent producing consumption goods. With the introduction of the BRW household production function into that environment, the correlation would presumably be substantially higher than their 0.10. A numerical comparison is reported in Section 5. 
Another issue is whether the statistics that serve as a basis for fact $(x)$ on page 3 include consumer durables. Empirically, this aggregate shares many of the properties of business investment, being highly volatile and strongly procyclical. Most model economies abstract from consumer durables and, one may argue, cannot hope to produce very procyclical hours in the consumption sector. In BRW, consumer durables are, to a large extent, the empirical counterpart to household capital, yet the hours spent producing them are not allocated to the consumption sector. For their benchmark parameter values, household investment is strongly countercyclical. This fact leaves some doubt as to how much has been resolved with regard to accounting for the procyclical hours in the consumption sector.

I have discussed two approaches to modeling household production, each of which may have an important bearing on labor-market fluctuations. The first emphasizes the use of nonmarket time to accumulate a durable, which is not necessarily tangible, in the home sector. The other approach is to think of nonmarket time as being combined with tangible market-produced durables to produce another consumption good. In either case, if these features can be shown to have quantitative importance, they will help to account for a considerable part of output and, in particular, hours varlability. Both cases share one characteristic, however: Their underpinnings, in the form of measurements, are still shaky.

Another model motivated by home production, or by the interaction of home and market production, is presented in Cho and Cooley (1994). Their idea is that there is a fixed cost associated with each day when people work. This cost can be motivated partly by the notion that some home production, such as child care, needs to be replaced. Moreover, Cho and Cooley assume an 
externality in the sense that this cost depends on the aggregate number of workers. They then show that introducing this feature potentially can lead to a substantial increase in the volatility of hours relative to that of productivity. However, strict calibration of the model to micro observations gives less encouraging results, and the authors conclude that the evident deviation shows that some important feature still is missing from their model environment.

\section{High- and Low-Wage Earners}

\section{Theory}

The model environments discussed so far assume that all workers are homogeneous. If there are substantial differences in cyclical behavior across demographic groups, then this assumption could bias considerably the estimate of the role of technology shocks. As fact (ix) in the Introduction indicates, an example of such a difference is the greater hours volatility of the low-wage earners as compared with high-wage workers.

A simple way to introduce heterogeneity in this class of economies is to divide the model population into groups according to skills. Kydland (1984a) considers two equal-sized groups, where the first is better skilled for market production than is the second. The resource constraint then can be written as

$$
c_{1 t}+c_{2 t}+x_{t} \leq z_{t} f\left(h_{t}^{e}, k_{t}\right)
$$

where $c_{1 t}$ and $c_{2 t}$ are consumption by the high- and low-skilled workers, respectively, and $h_{t}^{e}=\omega h_{1 t}+h_{2 t}$ is total labor input measured in qualityweighted units. If we divided the work force in two according to skills and 
used average per-person labor compensation to compute this welght, the numbers in Kydland (1984a) or in Ríos-Rull (1993a) suggest a value for $\omega$ of two or higher. The equilibriums studied are those corresponding to the Pareto problem of maximizing the welghted utilities of the two groups. (See Negishi [1960].) The weights are calibrated so as to yleld average hours spent in market activity comparable to those in the U.S. data when workers are divided into two similar-sized groups according to human capital.

The associated equilibrium is such that average consumption less labor income is greater for the low-wage earners than for those with high wages. Steady-state aggregate consumption has to satisfy the constraint

$$
c_{1}+c_{2}=w_{1} h_{1}+w_{2} h_{2}+b_{1}+b_{2}
$$

where $b_{i}$ stands for net nonlabor income for workers of type $i$. It consists of net capital income as well as any net transfers, $\tau_{i}$, from the other skill group, that is, $\tau_{1}=-\tau_{2}$. Thus, total steady-state nonlabor income, $b_{1}+b_{2}$, is simply the real interest rate, $r$, multiplied by the capital stocks. For each skill group, $b_{i}$ is defined such that $c_{i}=w_{i} h_{i}+b_{i}$. For the equilibriums reported in Kydland (1984a), the steady-state magnitude of $b_{2}$ exceeds that of $b_{1}$ by nearly 4 percent of GNP. Given what we know about relative capital income for the two groups, this means that some of $b_{2}$ has to be a transfer from the high-wage to the low-wage earners. In view of the amounts of such transfers that take place through the government as well as within the household, this magnitude does not appear unreasonable.

Kydland (1984a) compares the case in which the wage $\omega$ of the skilled workers relative to that of the unskilled is constant with the case in which this relative wage moves countercyclically by a small amount, say with a standard deviation of one-quarter of a percent. A finding is that, in the 
latter case, the standard deviation of aggregate unweighted hours rises by more than 20 percent relative to that of productivity. On the other hand, the fraction of output volatility accounted for by Solow residuals declines by about 10 percent. The model's cyclical relation between the relative wages of the skill groups is consistent with that reported by Reder (1962), although it would be interesting to have this empirical regularity investigated again using more recent, perhaps higher-frequency, data. Intuitively, it seems reasonable that the high-skilled workers are more adaptable in recessions, but that the skills of some, such as certain engineers, become obsolete in periods of rapid technological advance. There are, of course, numerous microstudies of the interaction in production of categories such as white- and blue-collar workers or workers with different levels of training.

This model economy introduces heterogeneity in a way that makes it tractable within an infinitely-lived-agent framework. It illustrates a channel through which skill differences may affect the role of technology shocks for the cycle in general and for the implled volatility of hours of work in particular. A sharper assessment of this importance will depend on measurements such as those suggested in the preceding paragraph. Moreover, since the equilibriums studied require transfers from the skilled to the unskilled of particular magnitudes, the reliability of the findings may depend on the presence of similar magnitudes in the actual economy. Although sizable transfers clearly do take place, their exact quantities are not easy to determine for the appropriate classification of people.

I have described an environment with the population divided into two different, but infinitely lived, groups. It abstracts from life-cycle behavior, for instance, which can be built into an overlapping-generations frame- 
work for mortal consumers. Until recently, however, it was difficult to see how such models could be calibrated while at the same time maintaining computational tractability. Economists' perspective on the feasibility of using aggregate equilibrium models with life-cycle behavior now has changed, in part as a consequence of research that develops further the quantitativetheoretic approach pioneered for such models by Auerbach and Kotlikoff (1987).

In the past few years, Ríos-Rull has led the way in developing and using overlapping-generations models in order to obtain quantitative answers to a variety of questions. Of particular interest here is his paper (1993a) on the interaction between household production and the choice of whether or not to become better skilled for market production. The paper is motivated to a large extent by fact $(i x)$ in the Introduction. The driving forces are the presence of home-produced goods with poor market substitutes and the possibility of choosing whether or not to acquire skills through schooling. In this model economy, meaningful heterogeneity arises even though everyone is born alike. The model can account well for some of the key movements both cross-sectionally and secularly. Cyclically, however, a remaining discrepancy is that, unlike the U.S. data, the volatility of the unskilled workers does not exceed that of the skilled workers in this model.

Measurement

An alternative to modeling explicitly the heterogeneity of workers in terms of skills for market production is to take account of these differences in the measurements to which models are compared. Given the central role played by the production function for aggregate theory in general and for business-cycle theory in particular, an important question is: How reliable 
are the available measurements of the labor input? For output and its components, the principles behind the measurements are those pioneered by Kuznets (1946) and Stone (1947) for national income and products accounts. According to these principles, steady-state or base-year prices are used to weight the different goods being summed up to form the aggregate real quantities. A similar approach is used for the capital stock. The difficulties for capital are perhaps even more severe, as the capital controversy between the two Cambridges illustrated. It is clear, however, that while Cambridge, England was right in theory, Cambridge, Massachusetts prevailed in practice. The capital-stock measurements have contributed to the important developments and insights in growth theory in the past 30 or 40 years. (See Solow [1970].) In contrast, the same NIPA principles typically have not been applied to the measurement of the labor input. Standard practice is to give equal weight to the hours of all workers, including people with dramatically different stocks of human capital. If the cyclical behavior of these workers differs widely, then the standard procedure of simply adding up the hours may produce a poor measure of the labor input.

From the viewpoint of a theory in which the production function is a central feature, it is natural to think of the labor input in efficiency units. One would then like to weight the hours of different individuals by their relative base-year prices in the same way that other NIPA quantity data are constructed. An indication of the urgency of this task is in Kydland (1984a). Using data from the PSID on about 1000 men over the age of 30 , which presumably is the least volatile major category of the labor force, and dividing them into five nearly equal groups according to years of schooling, he estimates that, over the eleven-year period of the sample, the least 
educated group changed their annual hours on the average by about 100 hours more for each percentage-point change in the unemployment rate than did the most educated group.

A more detailed study of this measurement issue is reported in Kydland and Prescott (1993). Using a sample from the PSID of nearly 5000 people consisting of all major demographic groups, they compare the cyclical behavior of two alternative measures of the labor input. Let $N_{t}$ be the number of people in the population in year $t$ and $h_{i t}$ person $i^{\prime} s$ hours of work in that year. The standard measure is simply to add up, in each period, the hours across all workers: $H_{t}=\sum_{i} h_{i t}$. Another measure is to multiply the hours of each individual by relative human-capital weights that do not change cyclically: $L_{t}=\sum_{i} \phi_{i} h_{i t}$. For the sample period there was little secular change in average real compensation per hour. Therefore, a fixed relative weight for person $i$ was constructed by dividing his or her total real labor earnings over all the years by total hours worked in those same years. That is, $\phi_{i}=\sum_{t} e_{i t} / \sum_{t} h_{i t}$, where $e_{i t}$ is real labor earnings of individual i in year $t$, and the summations are over all the years of the sample period for which observations for that person were available. This measure of the worker's "normal" efficiency is used in every period as the stand-in for his or her relative efficiency in market production.

The finding is that, if the sample were representative of the entire population, the standard measure of labor input would overstate the laborinput volatility by about 40 percent. This is a large number from the standpoint of business-cycle theory. Another finding is that the real hourly compensation of the quality-adjusted labor input is more procyclical than is the corresponding average compensation per unweighted hour. 


\section{Hours versus Employment Behavior}

Indivisible Labor

An important development in the understanding of hours volatility was made by Hansen (1985). In the models discussed so far, all the variability in hours takes the form of changes in hours per worker. Hansen went to the opposite extreme. In his environment, all the labor-input volatility takes the form of employment changes. There is a fixed cost of working, with the implication that everyone works either zero hours or some positive number $h_{1}$.

As an illustration, assume that the utility function is logarithmic (corresponding to $\sigma=1$ above):

$$
u\left(c_{t}, \ell_{t}\right)=\log c_{t}+\alpha \log \ell_{t} \text {. }
$$

To get around the nonconvexity implied by the binary choice of hours of work, assume instead that individuals choose the probability $\pi_{t}$ of working. In other words, a contract is traded between workers and firms to work $\bar{h}$ hours with probability $\pi_{t}$ and 0 hours with probability $1-\pi_{t}$. This means that the worker gets paid whether he works or not. (Hansen discusses in an appendix the interpretation in terms of insurance).

Individuals are identical ex ante, but the ex post outcome in every period depends on the lottery. Expected utility is

$$
\begin{gathered}
\mathrm{U}\left(c_{t}, \ell_{t}\right)=\pi_{t}\left[\log c_{t}+\alpha \log \left(1-h_{1}\right)\right]+\left(1-\pi_{t}\right)\left(\log c_{t}+\alpha \log 1\right) \\
=\log c_{t}+\alpha \pi_{t} \log \left(1-h_{1}\right) .
\end{gathered}
$$

Per-capita hours worked are simply $h_{t}=\pi_{t} h_{1}=1-\ell_{t}$, implying that $\pi_{t}=\left(1-\ell_{t}\right) / h_{1}$. Substituting this expression for $\pi_{t}$ in the utility function, we obtain the representative individual's utility function: 


$$
U\left(c_{t}, \ell_{t}\right)=\log c_{t}-\frac{\alpha \log \left(1-h_{1}\right)}{h_{1}} \ell_{t}+\text { constant. }
$$

In other words, the planner's utility function is linear in $\ell_{t}$. Thus, the startling finding is that the intertemporal elasticity of substitution in the aggregate can be very large even though, as a property of each individual's utility function, this elasticity has the much smaller value associated with the logarithmic utility function. Based on this model economy, Hansen found that Solow residuals could produce business cycles even more volatile than those observed in the postwar U.S. economy.

With the extreme assumption that the employment margin is where all the hours variabllity takes place, the implied estimate naturally overstates the role of technology shocks for the cycle. An economy that permits variation along both margins -- employment and hours-per-worker -- presumably would yield an estimate somewhere in between those of Hansen's model and those of a model with only hours-per-worker variation. Such an estimate is provided in Kydland and Prescott (1991).

\section{Two Margins}

The goal here is to construct a business-cycle model in which there is variation in labor input along both the hours-per-worker and the employment margin. In order to provide a credible estimate of the role of technology shocks, this model ought to mimic to a reasonable degree facts (ii) and (iv) in the Introduction.

In this economy, the obvious analog of the standard production function is $z_{t} f\left(h_{t} n_{t}, k_{t}\right)$, where $n_{t}$ is the number of workers and $h_{t}$ is hours per worker. This production function implies that the marginal product of labor input is the same no matter which of the two forms the change takes. A 
better assumption is that a fixed number of workers are assigned to each machine or, more generally, to each unit of capital input. Adding workers to a fixed stock of capital then reduces the marginal product in the usual way, while letting the existing workers operate the machines longer hours would, to a reasonable approximation, increase output in the same proportion; the production function is $z_{t} h_{t} f\left(n_{t}, k_{t}\right)$.

Another issue is how to deal with the labor indivisibility analogous to that in Hansen's economy. The economy still is inhabited by a large number of ex ante identical individuals, although some will not work ex post in every period. Some preliminary insight can be gained from a related oneperiod example from Hornstein and Prescott (1989):

Each agent is endowed with $\overline{\mathbf{k}}>0$ units of capital. Preferences with respect to consumption-work pairs $(c, h)$ are represented by their expected utility, $E[u(c, h)]$, where $h$ is the fraction of time allocated to market activity. For simplicity, I assume that $s=(c, h, k)$ is a member of $\mathrm{S}=\mathrm{C} \times \mathrm{H} \times \mathrm{K}$, where $\mathrm{C}, \mathrm{H}$, and $\mathrm{K}$ are finite sets. In practice, these sets could be constructed as a grid of values in the relevant range for each of the variables. For each individual, the commodity bundle is interpreted as a contract that obliges him to provide $k$ units of capital and $h$ units of time, for which he receives c units of the consumption good. The probability of an event $s=(c, h, k)$ is $x_{s}$.

In the business sector, adding the finite set $N$, let $A=H \times K \times N$ with elements of the type $a=(h, k, n)$. The choice is how many plants $z_{a}$ to operate for $h$ hours using $k$ units of capital and $n$ workers. An allocation satisfies the resource constraints if 


$$
\begin{aligned}
\sum_{B} c x_{b}-\sum_{a} h f(n, k) z_{a} & \leq 0 \\
-\sum_{B} k x_{b}+\sum_{a} k z_{a} & \leq 0 \\
-\sum_{b, k} x_{a}+\sum_{k} n z_{a} & \leq 0 \text { for all } h \in H .
\end{aligned}
$$

The first constraint says that the amount consumed is less than or equal to the quantity produced. According to the second constraint, the quantity of capital used in production cannot exceed the quantity available. The last constraints (one for each value of $h$ ) say that the number of people working in plants that are operated $h$ hours does not exceed the number of people working $h$ hours.

For this economy, as shown in Hornstein and Prescott, the competitive equilibrium can be obtained by solving a stand-in Pareto problem. This problem is a linear programming (LP) problem with the $x_{s}$ as variables:

$$
\max _{x \geq 0} \sum_{g} u(c, h) x_{s}
$$

subject to

$$
\begin{aligned}
& \sum_{s} x_{s}=1 \\
& \sum_{s}[c-f(1, k) h] x_{s} \leq 0 \\
& \sum_{s} k x_{s} \leq \bar{k} .
\end{aligned}
$$

A general property of the solution to an LP problem with three constraints is that at most three variables are positive. That is, there are no more than three combinations of $s=(c, h, k)$ such that $x_{s}>0$.

Now consider production and utility functions given by relations (1.2) and (1.3) with standard parameter values. It turns out that when the grids of the points in $S$ are made successively finer, the solutions to the corresponding planner's problems tend to cluster in such a way that at least two 
of the points that receive positive $x_{8}$ get closer and closer. As Hornstein and Prescott show, this pattern reflects the property that, when the sets $\mathrm{C}$, $H$, and $K$ contain infinitely many points ( $S$ is a subset of $\mathbb{R}_{+}^{3}$ ), then the solution to the LP problem implies mass on either one point or on two, depending on the parameter values for the utility and production functions.

When the equilibrium consumption vector places mass on only one point $\left(x_{s}=1\right.$ for some $\left.s=s_{1}\right)$, it is of the form $s_{1}=\left(c_{1}, h_{1}, k_{1}\right)$. Since $h_{1}>0$, everyone works the same number of hours. When there is mass on two points, $s_{0}$ and $s_{1}$, then the value of $h_{0}$ in $s_{0}$ is zero. Thus, some fraction of people work $h_{1}$ hours and recelve consumption $c_{1}$, while for everyone else $h_{0}$ is zero and consumption is $c_{0}$.

Business-Cycle Model

An analogous structure will now be embedded within a fully dynamic business-cycle model. This model will be calibrated to correspond to that with mass on two points. The variable $n_{t}$ will be the fraction of people who work in period t. A person working $h$ hours and using $k$ units of capital produces $\mathrm{zh}^{1-\theta}$ units of some intermediate good. This good, along with inventory services $y$, is an input to a CES production function.

For this economy, the aggregate resource constraint in period $t$ is

$$
c_{t}+x_{t}+m_{t} \leq\left[(1-\gamma)\left(z_{t} h_{t} n_{t}^{\theta} k_{t}^{1-\theta}\right)^{-\nu}+\gamma y_{t}^{-\nu}\right]^{-1 / \nu},
$$

where $m_{t}$ is the aggregate cost of moving people between the market and nonmarket sectors. This cost will be approximated by a quadratic function, $m_{t}=\mu\left(n_{t}-n_{t-1}\right)^{2}$. As suggested by Kydland and Prescott (1991), this specification is a stand-in for an environment in which there is a distribution of moving costs across the population, and those with the smallest cost are 
moved first. The moving-cost distribution is independent over time. This formulation gives rise to labor hoarding in this economy.

The cost of getting to work every day may also play a role. Most of that cost probably is in the form of time that is not enjoyed as leisure and does not contribute as an input in the production of goods. Such a cost is allowed for in the original model. Although it affects the calibration somewhat, it makes little difference to the cyclical properties and I ignore it here.

As in Section 1, the inventory stock is included as an input. This assumption is made partly for analytic reasons. One can then approximate the economy with inventories by a linear-quadratic economy. That larger inventories economize on the other two inputs can be justified in several ways. For example, by making longer production runs and thus holding larger inventories on the average, firms reduce equipment downtime associated with shifting from producing one good to another. For this economy, the observed procyclical behavior of the aggregate inventory stock is mimicked reasonably well.

The remainder of the model specification is analogous to that in Section 1. The laws of motion for finished and unfinished capital stocks are given by equations (1.4) and (1.5), and total investment by (1.6). Finally, I use the law of motion (1.1) for the technology level.

An implication analogous to that in Hornstein and Prescott is that the equilibrium can be computed by solving a social planner's problem:

$$
\max E \sum_{t=0}^{\infty} \beta^{t}\left[n_{t} u\left(c_{1 t}, 1-h_{t}\right)+\left(1-n_{t}\right) u\left(c_{0 t}, 1\right)\right]
$$

subject to 


$$
c_{t}=n_{t} c_{1}+\left(1-n_{t}\right) c_{0 t}
$$

and to the constraints just mentioned. The utility function $u$ is the standard one given by relation (1.3), where the elasticity of substitution already has been calibrated to equal one for reasons discussed in Section 1.

\section{Steady State and Calibration}

The steady state for this economy is its deterministic rest point, that is, the point resulting when the variance of the shock is zero. The steady state is important for two reasons. First, since this highly nonlinear model will be solved by first making a quadratic approximation, the steady state represents the point about which this approximation is made. More importantly, however, the properties of the steady state for the model economy correspond to analogous long-run relations in the actual economy that in many cases can be measured with high signal-to-noise ratios and are used in the calibration.

Some relations do not require much analysis of the model. Examples are NIPA relations for the model environment. Without loss of generality, I choose units such that steady-state output is one. Steady-state consumption and investment shares of GNP are set at 0.75 and 0.25 , respectively. For the United States in the postwar period, the inventory stock has been about a quarter of annual GNP. Thus, I set $y=1$. Steady-state $n$ corresponds to the long-run fraction of the working-age population who actually work and is taken to be 0.75 , while $h$, the steady-state fraction of time spent working, conditional on being in the market sector, is 0.40 . As an average of the entire population of the model economy, then, the time spent in market activity is 0.30 , or just over 30 hours per week. This is a standard magnitude for this relation and in line with the measurements by Ghez and Becker 
(1975).

The elasticities of substitution between consumption and leisure in utility and between capital and labor in production have been discussed already. Both equal one. There is less clear-cut evidence on which to base the value of the elasticity $1 /(1+v)$ between inventories and the composite input. It is probably quite small and $v$ therefore substantially larger than zero. I choose $v=3$. If the question dictates it, one should of course investigate the robustness of the answer to this choice.

A value for $J$ of three quarters is a reasonable compromise. Some capital goods of course take more time, and some less, to build. There is little evidence that the average time to build varies over the cycle. I assume that the resources needed are used up evenly throughout the construction period, that is, $\phi_{j}=1 / \mathrm{J}$ for all $\mathrm{j}$. The evidence is that the yearly depreciation rate is in the range of 8-10 percent. Since I assume no growth, I shall use the upper end of this range and assume $\delta=0.025$. This value, along with an investment share of output of 0.25 , corresponds to a yearly capital/output ratio of $2.5(k=10)$. Also, with no growth, the steady-state real interest rate $r$ equals $(1-\beta) / \beta$. A value for $r$ of 0.01 per quarter implies that $\beta$ is approximately 0.99 .

Before considering the remaining parameter values, we need to derive the steady-state implications of equilibrium behavior for the model environment. For this purpose it is convenient to work with the decentralized problems of the household and of the firm separately. (For a discussion of decentralization of the standard growth model, see Cooley and Prescott [1993].) I think of firms as being owned by the households, and the input factors as being rented or hired from these same households. For either problem, I initially 
take hours per period, $h$, as given. The remaining decision variables for the firm, then, are $n, k$, and $y$, and for the household $c_{0}, c_{1}$, and $n$. In the end, $h$ is determined from the equilibrium condition that the marginal product of working $h$ hours equals the negative of the ratio of marginal utilities with respect to hours and consumption.

\section{The Firm's Problem}

The firm is endowed with a technology whereby it uses labor, capital, and inventories as inputs to produce output of goods and services. Defining $q_{k}$ and $q_{y}$ to be the rental prices of capital and inventories, respectively, and $w_{h}=$ wh to be a worker's real earnings per period conditional on working $h$ hours, the firm maximizes in every period

$$
F\left(z h n^{\theta} k^{1-\theta}, y\right)-q_{k} k-q_{y} y-w_{h} n .
$$

In the steady state, the equilibrium $q_{y}$ equals $r$ and, with no additional time to build (that is, with $J=1$ ), the rental price of capital would be $r+\delta$. For multiple-period construction $(J>1)$, however, the real price $p_{k}$ of newly produced capital exceeds one because resources are tied up during the construction period. Defining the prices of $s_{j}$, the capital goods being built, to be $p_{j}$, for $j=1, \ldots, J-1$, we must have $p_{J-1}=\phi_{J}$. The other prices are determined recursively as

$$
p_{j-1}=(1+r) p_{j}+\phi_{j}, \quad j=2, \ldots, J-1
$$

The equilibrium steady-state price of a unit of productive capital, then, is

$$
p_{k}=\sum_{j=1}^{J} \phi_{j}(1+r)^{j-1}
$$

implying a steady-state rental price of $q_{k}=(r+\delta) p_{k}$.

Units in which to measure output, such that its steady-state quantity is 
one, are chosen by selecting the average $z$ appropriately. Turning to the inventory decision, the condition $F_{y}=q_{y}$ yields

$$
\gamma=q_{y} y^{p+1}
$$

Similarly, from the condition $F_{k}=q_{k}$ one obtains

$$
1-\theta=q_{k} k /\left(1-\gamma y^{-v}\right)=q_{k} k /(1-r y) \text {. }
$$

That is, the parameter $1-\theta$ equals the capital share of income net of the income share of the inventory input. Thus, both $\gamma$ and $\theta$ are quantified from relations between varlables or parameters whose values we already have determined. In particular, $\gamma$ equals 0.01 (implying that 1 percent of the model's national income can be attributed to inventories) and $\theta$ is approximately equal to 0.64 . Finally, the wage rate $w$, which is a parameter of the household's problem, is implied by $w_{h}=w h=F_{n}$.

\section{The Household's Problem}

The household's problem treats the capital income parametrically. Steady-state net capital income is

$$
b=q_{y} y+\left(q_{k}-\delta\right) k \text {, }
$$

or equivalently

$$
b=r y+r p_{k} k+r p_{1} \delta k+r p_{2} \delta k
$$

that is, the interest rate times each of the values of the four capital stocks. Given this steady-state net capital income, the household maximizes discounted utility subject to an infinite-period budget constraint. The resulting values of the variables, $c_{0 t}, c_{1 t}, n_{t}$, and $h_{t}$, clearly are dateindependent. Consequently, we can drop the time subscripts. The steadystate problem of the household then can be written as 


$$
\max (1-n) u\left(c_{0}, 1\right)+n u\left(c_{1}, 1-h\right)
$$

subject to

$$
(1-n) c_{0}+n c_{1} \leq w h n+b
$$

Maximization yields first-order conditions with respect to the variables $c_{0}, c_{1}$, and $n$. Moreover, hours per worker, $h$, has to satisfy the condition $-u_{h} / u_{c_{1}}=F_{h}$. These four conditions, along with the budget constraint, determine the Lagrange multiplier and four additional unknowns. These four will be $\alpha$ and $\sigma$ from the utility function, and $c_{0}$ and $c_{1}$. The resulting values are $\alpha=0.29, \sigma=2.41, c_{0}=0.57$, and $c_{1}=0.81$. We note that, in the steady state, those who work consume about 40 percent more than those who are not in the market sector.

The value of $\sigma$ warrants a comment. This value is larger than the value of 2.0 used in Kydland and Prescott (1991) and results mainly from a lower calibrated value of $h$, namely, 0.40 rather than 0.44 . With a total time allocation of about 100 hours per week, the value of 0.44 probably was a little too high. It may be easier to think about $\sigma$ in relation to the empirical finance literature if we multiply $1-\sigma$ by $\alpha$, thus obtaining the overall exponent on $c$ in the utility function. This exponent (whose value here is -0.4) should be comparable conceptually to what is used in finance studies that abstract from the time-allocation decision. As such, the implied degree of relative risk aversion is in the ballpark of what those studies find.

\section{Cyclical Properties of Model Economies}

The purpose of this section is to compare cyclical properties of four of the economies that I have discussed: (A) a homogeneous-worker economy similar to that in Kydland and Prescott (1982), but with standard utility func- 
tion; (B) as in (A), but with part of nonmarket time used to produce a durable household good; (C) as in (A), but including a household technology for using capital and labor as inputs to producing consumption goods (similar to BRW); (D) as in (A), but with two margins for changing the labor input as described in Section 4. All four environments include inventories in the same ratio to GNP. It takes three quarters to build new productive capital. Other sources of calibration that are common to these economies also are assigned the same values. These magnitudes are presented and motivated in the preceding section.

The differences in calibration across economies are as follows: In economies $(A)-(C)$, the fraction of time devoted to market activity is 0.3 as in Section 4, but all in the form of $h$, since by assumption $n$ is one. In economy (B), the magnitude of $\mu_{0}$ is set equal to 0.60 , which gives slightly more weight to current leisure in the utility function than in Kydland and Prescott (1982). The depreciation rate $\boldsymbol{\eta}$ for household capital equals 0.10 . In economy (C), the parameters of the aggregator function for consumption in the utility function and those of the household technology are assigned the same values as in BRW. In other respects, the economy is analogous to economy (A). For example, it includes the same curvature parameter $\sigma$, which is greater than that used by BRW, who employ a logarithmic utility function.

The statistics on which I focus, in addition to output and its two main components, are those corresponding to the aggregates listed in Table 1. They are summarized in Table 2, borrowing the format in BRW. The notation $h_{c}$ represents the hours spent producing consumption goods in the market economy, while $c_{m}$ is consumption goods produced in the market economy. This latter distinction is relevant only for economy (C). 
In the simplest version of the growth model, as modified in Section 1, the standard deviation of cyclical output is 1.25 percent. Introducing household capital produced solely by leisure raises the figure to 1.39 percent. The increase in hours volatility is substantially greater, however, while productivity volatility is lower, so that for economy (B) hours volatility actually is larger than that for productivity.

The household technology shock evidently has the potential to account for a substantial fraction of the business cycle. The comparison of economy (C) with economy (A), where the introduction of the household technology is the only difference, indicates a rise in output volatility from 1.25 to 1.60 percent. Moreover, productivity becomes substantially less correlated with the cycle.

The introduction of a distinction between employment and hours-perworker variation, along with the modifled production function in relation (4.1), raises the standard deviation of output from 1.25 to 1.55 percent. The latter figure was produced with the same value of the standard deviation of innovations to technology as in the other experiments. Allowing for variable capacity utilization, however, means that the standard expression for determining the Solow residuals no longer is theoretically correct. A way of checking the size of the bias is to use the standard method in the model economy to see if the varlance estimate is different from the variance of $\varepsilon\left(0.0076^{2}\right)$ used as input to the experiments. The resulting bias suggests that the estimate of the standard deviation from economy (D) should be reduced from 1.55 to 1.49 .

For economies (C) and (D), I report the statistics for hours $h_{c}$ devoted to the production of consumption goods. This variable, which in part moti- 
vated the study by BRW, no longer has a straightforward definition because of the presence of inventory changes. A considerable fraction of these changes presumably are in the form of consumption goods. The assumption made in Table 2 is that in every period the fraction of inventory change that is in the form of consumption goods is the same as that in final sales. This is probably a conservative assumption. Then even economy (D) implies procyclical $h_{c}$, indeed with a greater correlation coefficient with cyclical GNP than in BRW. But for the modified BRW economy, my economy (C), this correlation coefficient is as high as 0.48. Had the model economy included marketproduced consumer durables in a way implying that they were procyclical as in the data, then an even larger correlation coefficient presumably would result. Thus, it seems safe to say that fact $(x)$ on page 3 no longer can be regarded as a deviation of theory relative to the data.

\section{On-the-Job Learning}

In constructing a model environment with heterogeneous workers, Kydland (1984a) assumes that the division of human capital between the two groups is given. That assumption precludes consideration of issues that relate to the timing of the accumulation of human capital over the cycle. As Mincer (1962, p. S73) concludes: "Investment in on-the-job training is a very large component of total investment in education in the United States economy." Human capital of this form thus is large enough so that, by abstracting from its accumulation when evaluating the role of technology shocks, one risks omitting a potentially important propagation mechanism. One may guess a priori that introducing on-the-job training will change the cyclical properties of several aggregates, perhaps of labor-input and productivity variables in 
particular. The main question, however, is to what extent the estimate of the cyclical role of technology shocks is affected.

An example of a tractable specification is to assume that workers enter the labor force at the lowest efficiency level and accumulate skills through the process of learning by doing for I periods. Let $e_{i t}, i=0, \ldots, I$, be the number of workers at efficiency level $i$ at time $t$, where $e_{0 t}$ represents the bottom of the skill distribution. Consider the following laws of motion:

$$
\begin{aligned}
& e_{1+1, t+1}=(1-\eta) e_{1 t}, \quad 1=0, \ldots, I-2, \quad \text { and } \\
& e_{I, t+1}=(1-\eta)\left(e_{I-1, t}+e_{I t}\right) .
\end{aligned}
$$

In other words, a fraction $\eta$ of the workers at each level lose their previously accumulated skills or "die." In the steady state, a corresponding number reenter at the inexperienced level. The total number of workers in period $t$ is $n_{t}=\sum_{1=0}^{1} e_{1 t}$. If the relative efficiencies are $\pi_{0}<\pi_{1}<\ldots<\pi_{1}$, where I normalize $\pi_{0}$ to one, then the corresponding quality-adjusted number is $e_{t}=\sum_{i=0}^{I} \pi_{i} e_{i t}$. This variable replaces $n_{t}$ in the production function.

The rest of the model is as in Section 4. Indeed, that economy is a special case (for $\Delta \pi=0$ ) of that considered here. With on-the-job learning, I state variables are added. With the computational method used, computer time increases a little, but there is no practical difficulty in setting up the computational experiments.

Assume that the absolute increments to $\pi_{1}$ are equal at all stages, that is, $\Delta \pi_{i}=\pi_{i}-\pi_{i-1}$ are the same for all $i$. This means, of course, that the percentage increases get smaller at each higher stage. I choose I = 8 and $\Delta \pi=0.05$, so that the most highly skilled workers are 40 percent more productive than those just entering the market sector. This is a compromise. 
Measurements probably would indicate steeper growth of efficiency at the initial stages and flatter growth at the later ones, with growth of some magnitude continuing after two years. The attrition rate, $\eta$, is set equal to 0.08 per quarter. Consequently, in the steady state, about half of the model's working population is in the highest earning group.

The comovements of the various aggregates with GNP and most of the relative volatilities are quite similar to those for the case of $\Delta \pi=0$. The main difference is that the standard deviation of output drops by 0.10 . In other words, Solow residuals now account for a slightly smaller fraction of the business cycle.

It has been suggested that, with human capital, different measurements are needed for the Solow residuals. This is not necessarily so. The situation is analogous to that in Kydland and Prescott (1991), where the authors permit variation in the number of hours a plant is operated, whlle the measurements of Solow residuals do not assume this. The magnitudes of the technology shocks going into the model are known. One can then measure the shocks in the model in the same way that they are measured in the data, and estimate the magnitude of the bias. For Kydland and Prescott, this procedure led to a slight reduction in the estimate of the fraction of the output variance accounted for.

\section{Conclusion}

This paper has presented variants of what can be regarded as the dominant framework of shared knowledge in aggregate economics. It is a framework within which one can organize and interpret NIPA data. The particular choice of model environment within this framework of course depends on the question 
to be addressed. The question of the role of shocks to aggregate production technology for the business cycle has received considerable attention in the past ten years. In this paper I have focused on the extent to which the estimate of this role depends on the model specification as it relates to the labor market in particular. To some extent, the different environments represent a progression over time in our understanding of the role of the labor input.

As we have seen, in spite of using an identical stochastic process for the impulse -- the technology shock in the market sector -- in each of the economies, the resulting volatility of GNP across models can be quite different. In other words, the roles of the propagation mechanisms are of central importance. In choosing models to consider, I have focused on the extent to which they represent different specifications of features that affect aggregate behavior as reflected more or less directly in the labor market.

In the initial development and use of this framework, some features of the workings of the labor market, especially the volatility of aggregate hours of work and the correlation between hours and productivity, were regarded as important deviations relative to theory. As theory and measurements have progressed, however, the status of these features as deviations has diminished. Better abstractions have been developed, for instance, to indicate that a great deal of aggregate intertemporal substitution of hours is what the theory predicts. From a measurement standpoint, evidence suggests that the volatility of the labor input, which one would like to measure by weighting the hours of different workers according to their normal efficiency, is considerably less than is the unweighted hours variability. The high correlation between hours and productivity, of course, is to be expected 
in environments with only technology shocks as a source of impulse. As illustrated in the exercise with shocks to household production added, the presence of other impulses will reduce that correlation. This has also been demonstrated with government shocks as the additional impulse (Christiano and Eichenbaum [1992]).

Among other things, I have discussed ways in which the propagation of shocks via the labor market is affected through interaction of the business and household production. It is probably fair to say that we know mainly about household production's potential to play a significant role. A clearer answer about its role will have to await measurements that have not yet been carried out. This is an important area of future research. Another question is whether the findings that use environments with adjustment along both the intensive and extensive margins are affected by the degree of insurance assumed in those models.

Many recent contributions to the understanding of the labor market and the cycle have been omitted from this overview. For example, while Hansen (1985) shows that intertemporal substitution in the aggregate may be much larger than that reflected in individuals' preferences, Smith (1989) finds a tendency in the same direction due to asymmetric information between workers and firms about the workers' skills. I did not focus on the countercyclical labor share of national income observed in the data. Ways of accounting for this fact are studied in Danthine and Donaldson (1990), using a contracting set-up, and in Gomme and Greenwood (1993).

It may be surprising to some that I make few references to micro labor studies, given the amount of data to which they have access and their potential importance as sources of calibration. The main reason is that much of 
that literature has been concerned with measurements that, with our modern general equilibrium language, do not map naturally into model parameters. Examples are demand and supply elasticities. For instance, low supply elasticities are interpreted as evidence of individuals' limited willingness to substitute intertemporally. The insight from Hansen's (1985) economy suggests, however, that this has little relevance to aggregate questions.

I have already listed some interesting measurement issues that remain for future research. On the theory side, many features of the labor market have received little attention and also represent interesting research areas for the future. Examples are the role of the differences of skills across workers for market production, the role of variation in capacity utilization and its implications for the aggregate production function, and the role of less-than-perfect insurance for workers against shocks. Some of these issues, to the extent that their source of importance is heterogeneity across workers, are surveyed in Ríos-Rull (1993b). 


\section{Bibliography}

Auerbach, A. J., and L. J. Kotlikoff. 1987. Dynamic Fiscal Policy. Cambridge: Cambridge University Press.

Benhabib, J., R. Rogerson, and R. Wright. 1991. "Homework in Macroeconomics: Household Production and Aggregate Fluctuations." Journal of Political Economy 99:1166-87.

Brock, W. A., and L. J. Mirman. 1972. "Optimal Economic Growth and Uncertainty: The Discounted Case." Journal of Economic Theory 4:497-513.

Cho, J. O., and T. F. Cooley. 1994. "Employment and Hours over the Business Cycle." Journal of Economic Dynamics and Control, forthcoming.

Christiano, L. J., and M. Eichenbaum. 1992. "Current Real Business Cycle Theory and Aggregate Labor Market Fluctuations." American Economic Review 82:430-50.

Cooley, T. F., and E. C. Prescott. 1993. "Economic Growth and Business Cycles." In T. F. Cooley (ed.), Frontiers of Business Cycle Research, forthcoming.

Danthine, J. P., and J. Donaldson. 1981. "Stochastic Properties of Fast vs. Slow Growing Economies." Econometrica 49:1007-33. . 1990. "Efficiency Wages and the Business Cycle Puzzle." European Economic Review 34:1275-1301.

Eichenbaum, M., and L. P. Hansen. 1990. "Estimating Models with Intertemporal Substitution Using Aggregate Time Series Data." Journal of Business and Economic Statistics 8:53-69.

Ghez, G., and G. S. Becker. 1975. The Allocation of Time and Goods over the Life Cycle. New York: Columbia University Press.

Gomme, P., and J. Greenwood. 1993. "On the Cyclical Allocation of Risk." Journal of Economic Dynamics and Control, forthcoming.

Greenwood, J., and Z. Hercowitz. 1991. "The Allocation of Capital and Time over the Business Cycle." Journal of Political Economy 99:1188-1214.

Hansen, G. D. 1985. "Indivisible Labor and the Business Cycle." Journal of Monetary Economics 16:309-27. 
Hornstein, A., and E. C. Prescott. 1989. "The Firm and the Plant in General Equilibrium Theory." Working Paper, Federal Reserve Bank of Minneapolis.

Hotz, V. J., F. E. Kydland, and G. S. Sedlacek. 1988. "Intertemporal Preferences and Labor Supply." Econometrica 52:335-60.

Kuznets, S. 1946. National Income: A Summary of Findings. New York: National Bureau of Economic Research, Twenty-fifth Anniversary Series.

Kydland, F. E. 1984a. "Labor Force Heterogeneity and the Business Cycle." CarnegieRochester Conference Series on Public Policy 21:173-208. . 1984b. "A Clarification: Using the Growth Model to Account for Fluctuations." Carnegie-Rochester Conference Series on Public Policy 21:225-30.

Kydland, F. E., and E. C. Prescott. 1982. "Time to Build and Aggregate Fluctuations." Econometrica 50:1345-70.

. 1990. "Business Cycles: Real Facts and a Monetary Myth." Federal Reserve Bank of Minneapolis, Quarterly Review 14:3-18.

. 1991. "Hours and Employment Variation in Business Cycle Theory." Economic Theory 1:63-81.

. 1993. "Cyclical Movements of the Labor Input and Its Implicit Real Wage."

Federal Reserve Bank of Cleveland, Economic Review 29/2:12-23.

Lucas, R. E., and L. A. Rapping. 1969. "Real Wages, Employment, and Inflation." Journal of Political Economy 77:721-54.

Mincer, J. 1962. "On-the-Job Training: Costs, Returns, and Some Implications." Journal of Political Economy 70:S50-79.

Murphy, K., A. Schleifer, and R. Vishny. 1989. "Building Blocks of Market Clearing Business Cycle Models." National Bureau of Economic Research, Macroeconomics Annual 247-87.

Negishi, T. 1960. "Welfare Economics and Existence of an Equilibrium for a Competitive Economy." Metroeconomica 12:92-97.

Prescott, E. 1986. "Theory Ahead of Business-Cycle Measurement." CarnegieRochester Conference on Public Policy 24:11-44; reprinted in the Federal Reserve Bank of Minneapolis Quarterly Review 10:9-22. 
Reder, M. W. 1960. "Wage Differentials: Theory and Measurement." In Aspects of Labor Economics. New York: National Bureau of Economic Research.

Rios-Rull, V.-J. 1993a. "Working in the Market, Working at Home and the Acquisition of Skills: A General Equilibrium Approach." American Economic Review 83:893-907. . 1993b. "Models with Heterogeneous Agents." In T. F. Cooley (ed.), Frontiers of Business Cycle Research, forthcoming.

Rogerson, R. 1984. "Topics in the Theory of Labor Markets." Unpublished Ph.D. dissertation, University of Minnesota.

. 1988. "Indivisible Labor, Lotteries, and Equilibrium." Journal of Monetary Economics 21:3-16.

Smith, B. 1989. "A Business Cycle Model with Private Information." Journal of Labor Economics 7:210-37.

Solow, R. M. 1957. "Technical Change and the Aggregate Production Function." Review of Economics and Statistics 39:312-20. 1970. Growth Theory: An Exposition. New York: Oxford University Press.

Stokey, N., and R. E. Lucas, with E. C. Prescott. 1989. Recursive Methods in Economic Dynamics. Cambridge, Mass.: Harvard University Press.

Stone, R. 1947. "Definition and Measurement of the National Income and Related Totals." Appendix to Measurement of National Income and Construction of Social Accounts. Geneva: United Nations. 
Table 1

Cyclical Behavior of U.S. Labor-Market Aggregates

Deviations from Trend

Quarterly, 1954.I - 1991.II

\begin{tabular}{|c|c|c|c|c|c|c|c|c|c|c|c|c|}
\hline \multirow[b]{2}{*}{ Variable $x$} & \multirow{2}{*}{$\begin{array}{l}\text { Volatility } \\
\text { (\% Std. Dev.) }\end{array}$} & \multicolumn{11}{|c|}{ Cross Correlation of Real GNP with } \\
\hline & & $x(t-5)$ & $x(t-4)$ & $x(t-3)$ & $x(t-2)$ & $x(t-1)$ & $x(t)$ & $x(t+1)$ & $x(t+2)$ & $x(t+3)$ & $x(t+4)$ & $x(t+5)$ \\
\hline Real Gross National Product & 1.72 & -0.02 & 0.16 & 0.38 & 0.63 & 0.85 & 1.00 & 0.85 & 0.63 & 0.38 & 0.16 & -0.02 \\
\hline Hours (Household Survey) & 1.49 & -0.10 & 0.05 & 0.25 & 0.46 & 0.70 & 0.86 & 0.85 & 0.74 & 0.58 & 0.38 & 0.17 \\
\hline Employment & 1.09 & -0.17 & .0 .03 & 0.16 & 0.38 & 0.63 & 0.83 & 0.88 & 0.80 & 0.65 & 0.46 & 0.25 \\
\hline Hours per Worker & 0.54 & 0.07 & 0.20 & 0.36 & 0.49 & 0.64 & 0.70 & 0.58 & 0.42 & 0.28 & 0.12 & -0.02 \\
\hline Hours (Establishment Survey) & 1.66 & -0.23 & .0 .07 & 0.14 & 0.39 & 0.67 & 0.88 & 0.91 & 0.80 & 0.63 & 0.42 & 0.22 \\
\hline GNP/Hours (Household Survey) & 0.87 & 0.12 & 0.23 & 0.33 & 0.47 & 0.50 & 0.51 & 0.22 & -0.01 & -0.24 & -0.32 & -0.34 \\
\hline GNP/Hours (Establishment Survey) & 0.82 & 0.41 & 0.47 & 0.51 & 0.53 & 0.44 & 0.32 & -0.06 & -0.30 & -0.47 & -0.50 & -0.49 \\
\hline $\begin{array}{l}\text { Average Hourly Real Compensation } \\
\text { (Business Sector) }\end{array}$ & 0.93 & 0.35 & 0.39 & 0.41 & 0.43 & 0.41 & 0.35 & 0.25 & 0.16 & 0.05 & -0.07 & -0.18 \\
\hline $\begin{array}{l}\text { Real Employee Compensation (NIPA)/ } \\
\text { Hours (Household Survey) }\end{array}$ & 0.65 & -0.11 & -0.11 & .0 .13 & 0.06 & 0.02 & 0.10 & 0.13 & 0.14 & 0.10 & 0.08 & 0.04 \\
\hline Real Employee Compensation (NIPA) & 1.54 & .0 .14 & 0.00 & 0.18 & 0.41 & 0.67 & 0.88 & 0.88 & 0.76 & 0.59 & 0.38 & 0.18 \\
\hline Employee Compensation (NIPA)/GNP & & -0.21 & -0.32 & -0.44 & -0.53 & -0.51 & .0 .46 & -0.13 & 0.13 & 0.32 & 0.39 & 0.38 \\
\hline
\end{tabular}

Source: Citicorp's Citibase data bank. 
Table 2

Statistical Properties of Model Economies

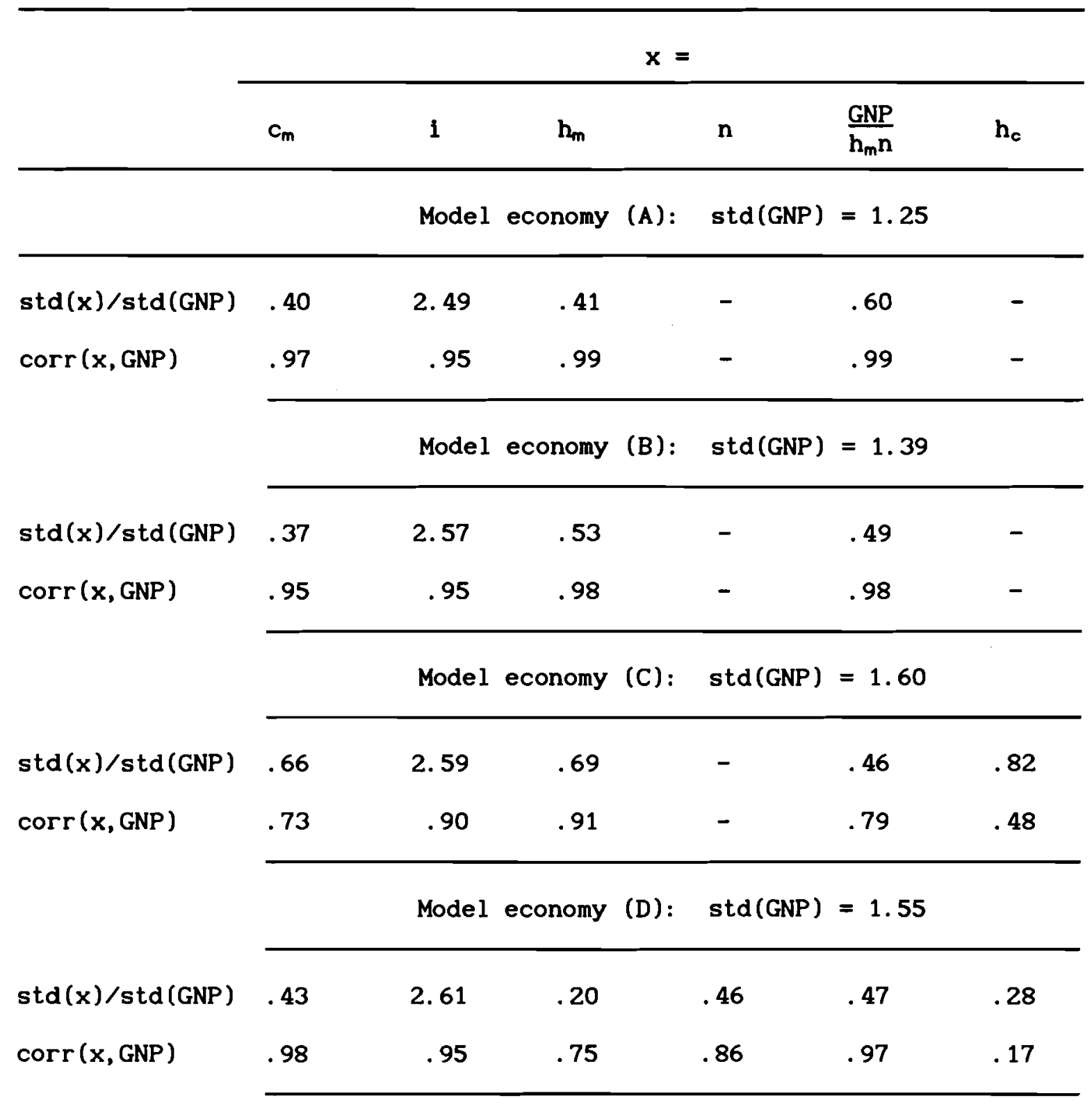

Source: Author's calculations. 


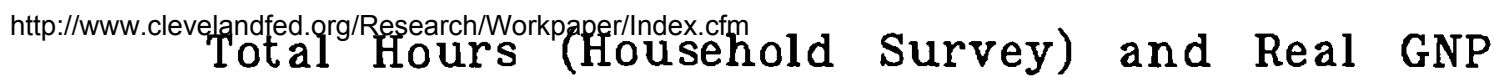

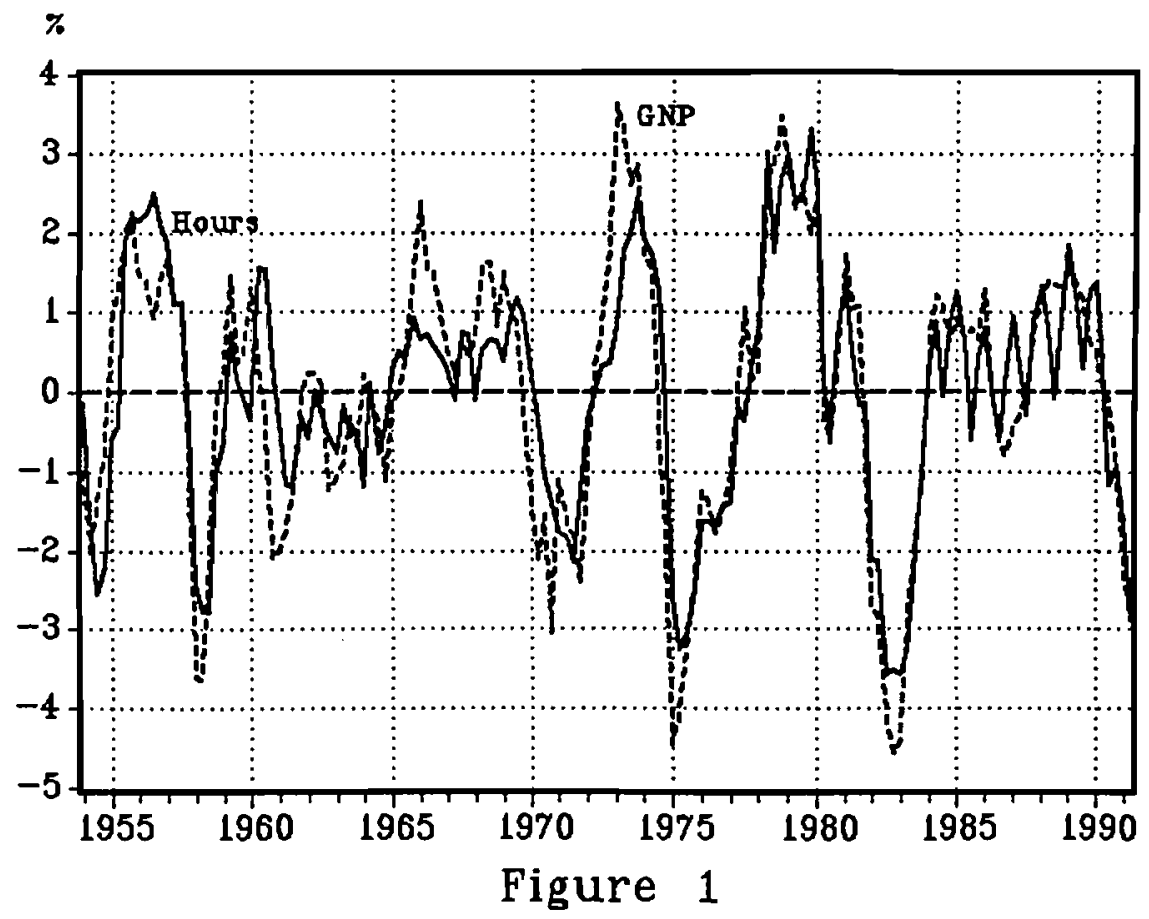

Hours per Worker and Real GNP

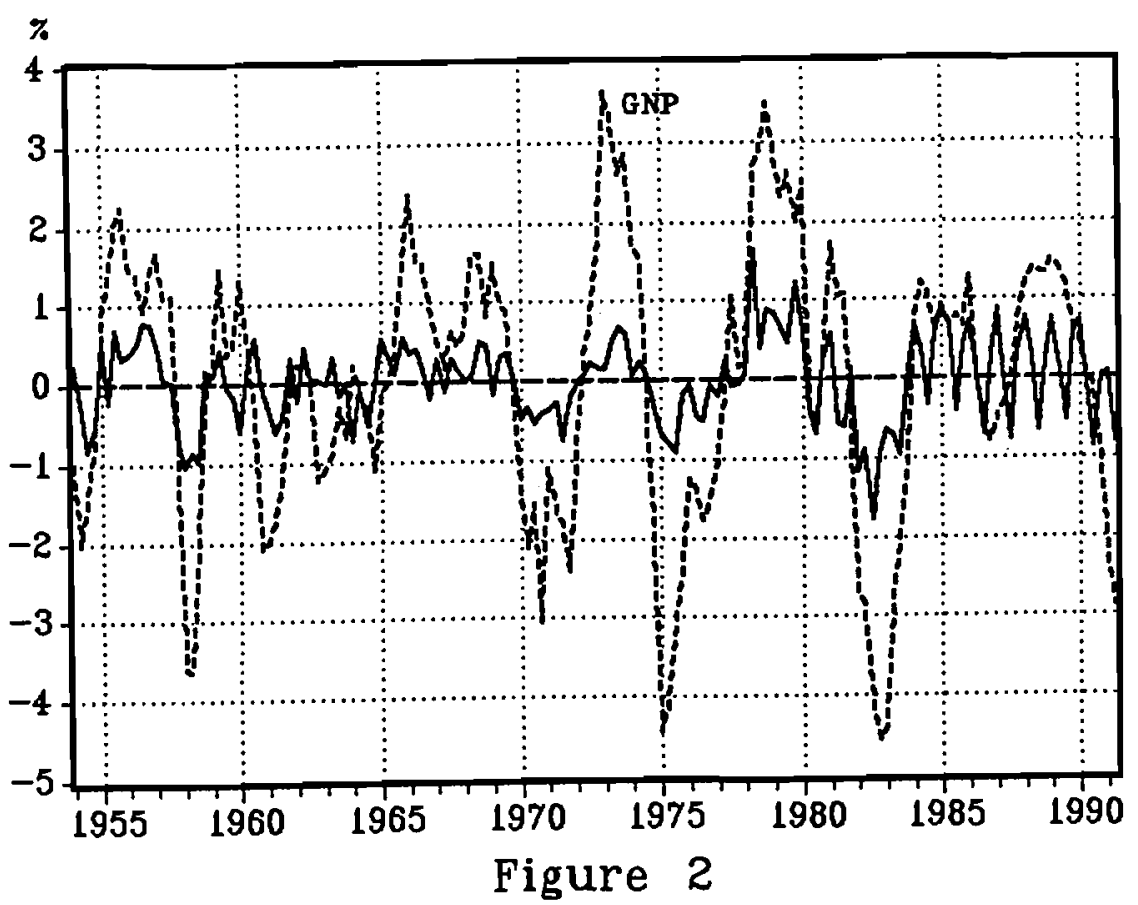

Source: Author's calculations. 
http://www.clevelandfed.oforadrch Emaderyment and Real GNP

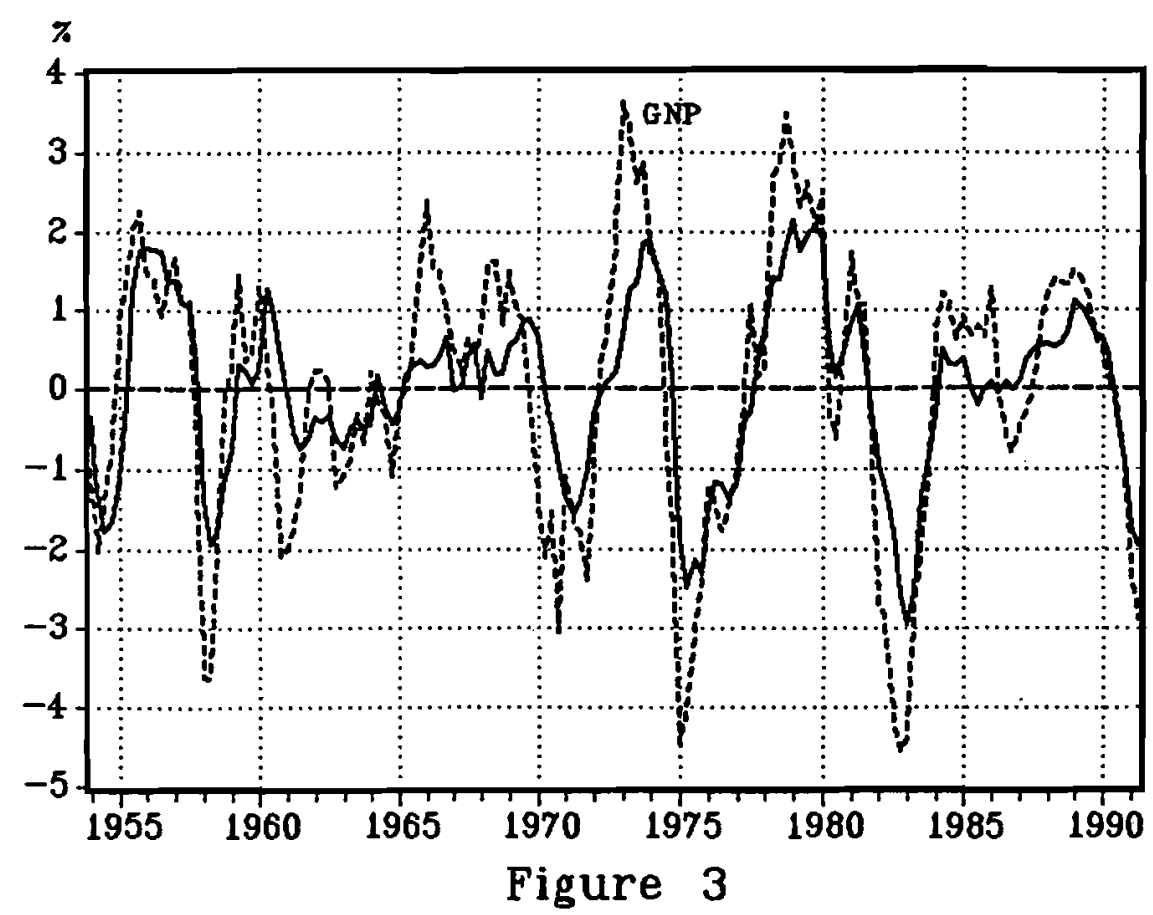

Total Hours (Establishment Survey) and Real GNP

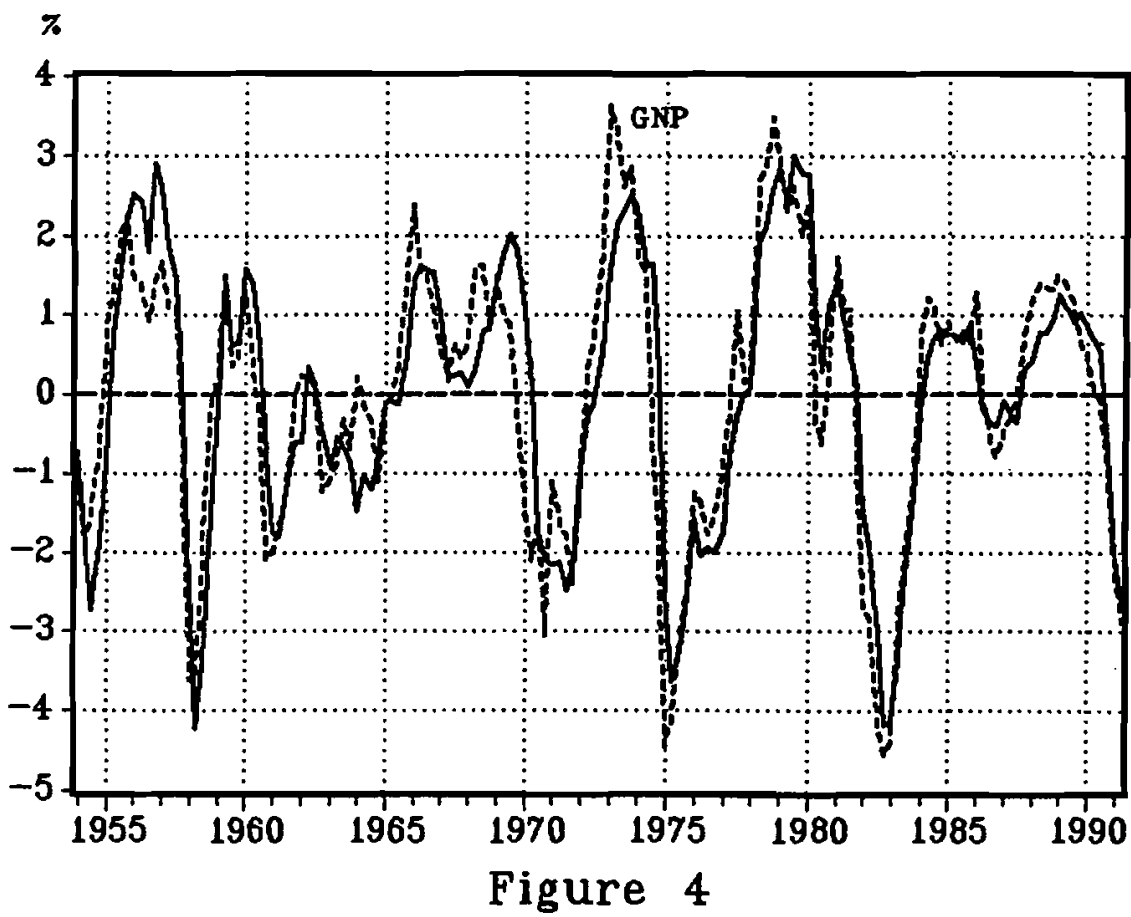

Source: Author's calculations. 


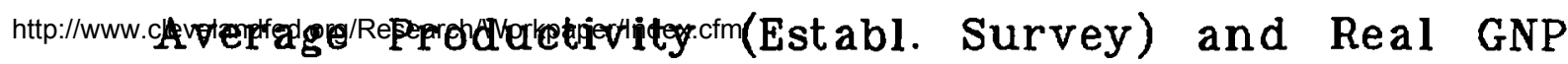

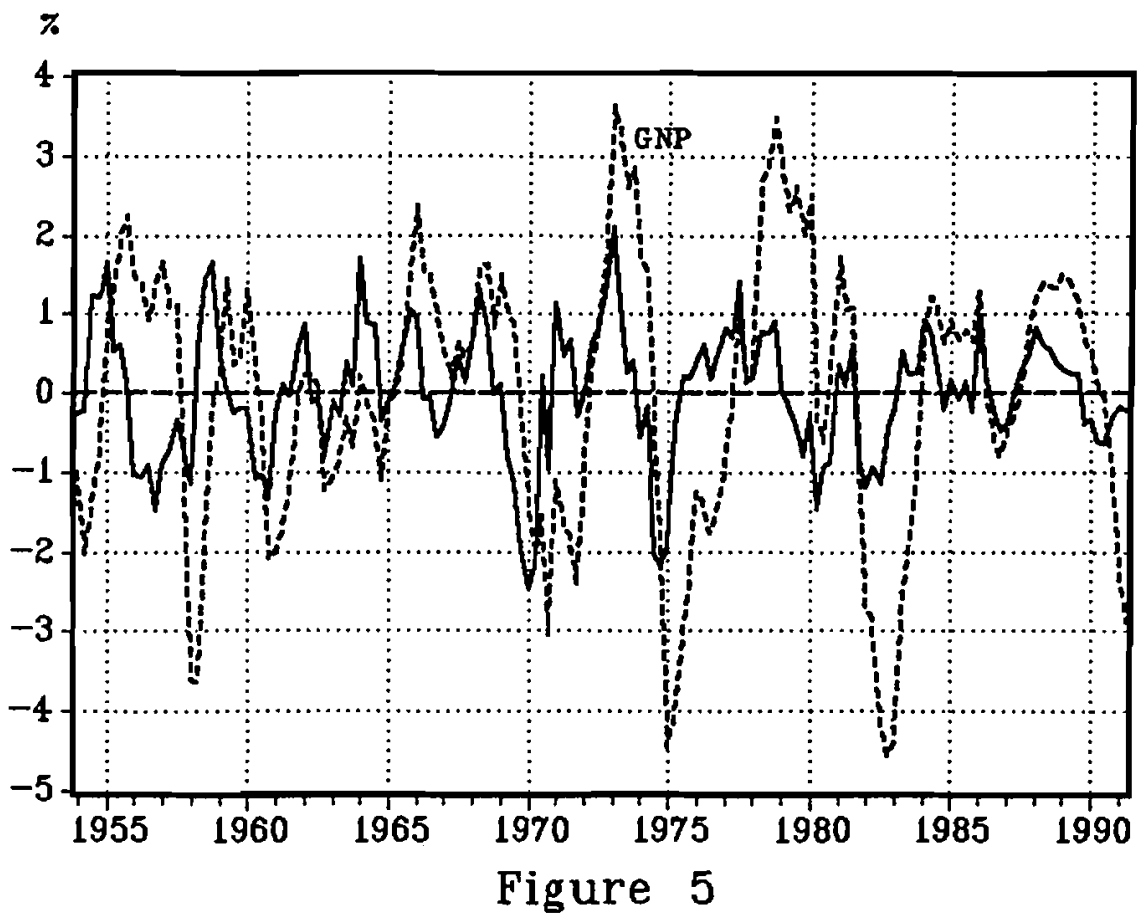

Average Hourly Real Compensation and Real GNP

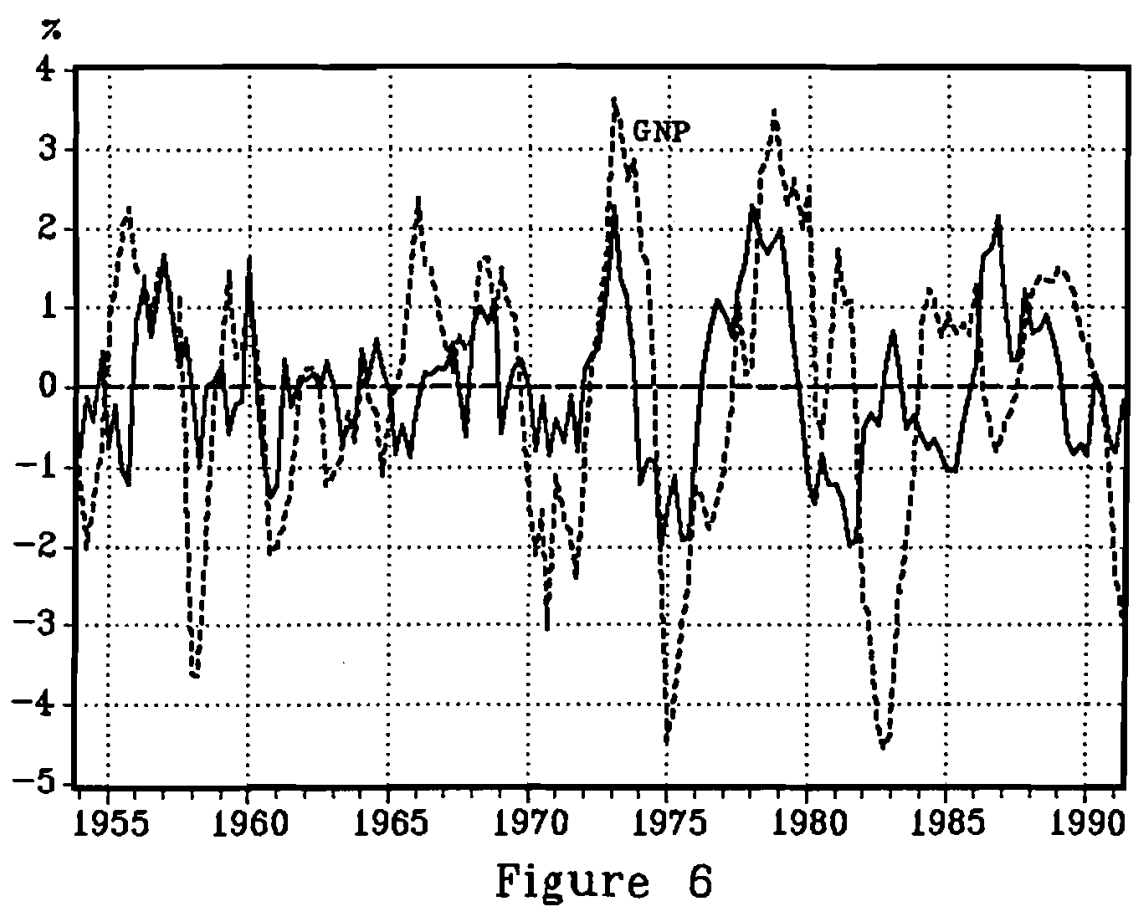

Source: Author's calculations. 